\title{
Development and Validation of Liquid Chromatography-Tandem Mass Spectrometry Methods for Determination of Beta-Lactams, Macrolides, Fluoroquinolones, Sulfonamides and Tetracyclines in Surface and Drinking Water from Rio de Janeiro, Brazil
}

\author{
Mychelle A. Monteiro, ${ }^{*, a, b}$ Bernardete F. Spisso, ${ }^{b}$ Rosana G. Ferreira, ${ }^{b}$ Mararlene U. Pereira, ${ }^{b}$ \\ Jônatas V. Grutes, ${ }^{b}$ Bárbara R. G. de Andrade ${ }^{c}$ and Luiz A. d'Avila ${ }^{a}$ \\ aPrograma de Pós-Graduação em Engenharia de Processos Químicos e Bioquímicos, \\ Escola de Química, Universidade Federal do Rio de Janeiro (UFRJ), Av. Horácio Macedo 2030, \\ Cidade Universitária, 21941-909 Rio de Janeiro-RJ, Brazil \\ ${ }^{b}$ Departamento de Química, Instituto Nacional de Controle de Qualidade em Saúdel \\ Fundação Oswaldo Cruz (INCQS/FIOCRUZ), Av. Brasil, 4365, Manguinhos, 21040-360 Rio de Janeiro-RJ, Brazil \\ 'Unidade Técnica de Exposição Ambiental, Ocupacional e Câncer, Coordenação de Prevenção e Vigilância (Conprev), \\ Instituto Nacional de Câncer (INCA), R. Marquês de Pombal 125, 20230-240 Rio de Janeiro-RJ, Brazil
}

\begin{abstract}
Two analytical methods for determination of five antibiotics classes in surface water and drinking water samples were developed and validated based on solid phase extraction followed by high-performance liquid chromatography coupled to tandem mass spectrometry. Two distinct chromatographic gradients were used according to the polarity of the different pharmaceuticals. The methods were applied for the quantification of 46 analytes belonging to beta-lactams, macrolides, fluoroquinolones, sulfonamides and tetracyclines classes. Validation results showed recoveries above $75 \%$ for the studied analytes in water samples. The method limits of detection calculated for the surface water and drinking water samples were, respectively, from 1 to $12 \mathrm{ng} \mathrm{L}^{-1}$ and from 0.15 to $20 \mathrm{ng} \mathrm{L}^{-1}$. The method limit of quantification ranged from approximately 3 to $38 \mathrm{ng} \mathrm{L}^{-1}$ for surface water samples and from 0.5 to $64 \mathrm{ng} \mathrm{L}^{-1}$ for drinking water samples. The methods showed to be linear over the range of 25 to $1000 \mathrm{ng} \mathrm{L}^{-1}$ with coefficients of determination greater than 0.94. Amoxicillin, cephalexin and sulfamethoxazole as high as $105 \mathrm{ng} \mathrm{L}^{-1}$ were found in surface water and erythromycin, azithromycin and clarithromycin up to $35 \mathrm{ng} \mathrm{L}^{-1}$ could also be found in surface water. Clarithromycin, cefaclor, oxacillin, sulfamethoxazole and troleandomycin were detected in the lower range up to $10 \mathrm{ng} \mathrm{L}^{-1}$ in drinking water.
\end{abstract}

Keywords: antibiotics, surface water, drinking water, mass spectrometry, emergence pollutants

\section{Introduction}

Antibiotics represent one of the most used class of drugs worldwide ${ }^{1}$ and correspond to the largest category of compounds used in human and veterinary medicine, as growth promoters or for therapeutic purposes. ${ }^{2}$ As regards to antimicrobials used in human medicine, non-prescribed medicines are consumed at home, and prescribed ones are consumed in hospitals and clinics. ${ }^{3}$ Individuals affected by infectious diseases use specific antibiotics, and after administration, the molecules are absorbed, distributed, metabolized partially, and finally excreted from the body. The metabolism eliminates substances in excess and other

*e-mail: mychelle.monteiro@incqs.fiocruz.br, mycalal@gmail.com xenobiotics via a series of enzymatic biotransformations and converts them into more polar and hydrophilic compounds. ${ }^{4}$ These substances were developed to be persistent, keeping its chemical properties, with a therapeutic purpose and after use, about 50 to $90 \%$ of a drug dose is excreted and persists in the environment. ${ }^{5}$ The occurrence of antibiotics in the aquatic environment and drinking water (DW) has raised questions about impacts on the environment and public health. The adverse effects caused by pharmaceutical compounds include aquatic toxicity, development of resistance in pathogenic bacteria, genotoxicity and endocrine disorders. ${ }^{6,7}$

Several methods have been developed to extract antibiotics in water. Currently, liquid chromatography-tandem mass spectrometry (LC-MS/MS) is the technique most widely used in analysis of drugs in complex environmental 
samples and have shown to be a sensitive analytical tool that leads to efficient results and lower detection (LOD) and quantification limits (LOQ) (in the range from $\mu \mathrm{g} \mathrm{L^{-1 }}$ to $n g \mathrm{~L}^{-1}$ ), and generate reliable data in the identification of several molecules. ${ }^{8}$ LC-MS/MS comprises a separation and a detection technique that provides structural confirmation of the analyzed compounds. ${ }^{8}$ A good chromatographic separation is advisable in order to reduce matrix effects, which usually results in suppression or, less frequently, signal enhancement. ${ }^{8}$ To minimize matrix interference, water extracts are generally cleaned up and pre-concentrated by solid-phase extraction (SPE), mainly using HLB cartridges. The use of SPE cartridges may greatly influence the recoveries of target compounds. ${ }^{8}$ Sample preparation is a crucial step in environmental analysis. It is highly influenced by the physical and chemical analytes properties and by matrices. The main objectives of sample preparation are to extract and concentrate the analytes of interest, removing sample matrix interferences for subsequent chromatographic analysis. The whole analytical procedure typically includes five steps: sampling, sample preparation, chromatographic separation, detection and data analysis. The most important part of the analytical process is sample preparation because it can take more than $80 \%$ of the total analysis time. ${ }^{8}$

Some information about contamination of Brazilian aquatic environment by antibiotics has been published in the form of dissertations and theses, but scientific papers are very scarce. The studies have been most accomplished in the southern and southeast of Brazil, and for this reason research in other geographical areas is necessary in order to obtain a complete panorama of the country. ${ }^{9-14}$

The watershed of Guandu River has a fundamental role for Rio de Janeiro metropolitan region where approximately 12.2 million inhabitants live. This watershed is very important because it is the only option for subsistence and development of the Metropolitan Region of the State of Rio de Janeiro. Its waters supply the second largest metropolitan region of the country, and for several productive sectors, such as the steel, petrochemical, clothing, food and beverage industries, among others, and also as a water body for the collection of domestic and industrial sewage. ${ }^{15}$

The aim of this study was to develop and validate a methodology to determine the antimicrobial residues of beta-lactams (BL), macrolides (MC), fluoroquinolones (FQ), sulfonamides (SF) and tetracyclines (TC) classes in river surface water $(\mathrm{SW})$ and DW samples in the state of Rio de Janeiro (Brazil). These methods were developed based on US EPA method $1694^{16}$ to determine pharmaceuticals in environmental samples by high performance liquid chromatography-tandem mass spectrometry (HPLC-MS/MS). The methods was applied for quantification of 46 analytes of BL, MC, FQ, SF and TC classes in nine SW and ten DW samples collected in the state of Rio de Janeiro (Figure 1).

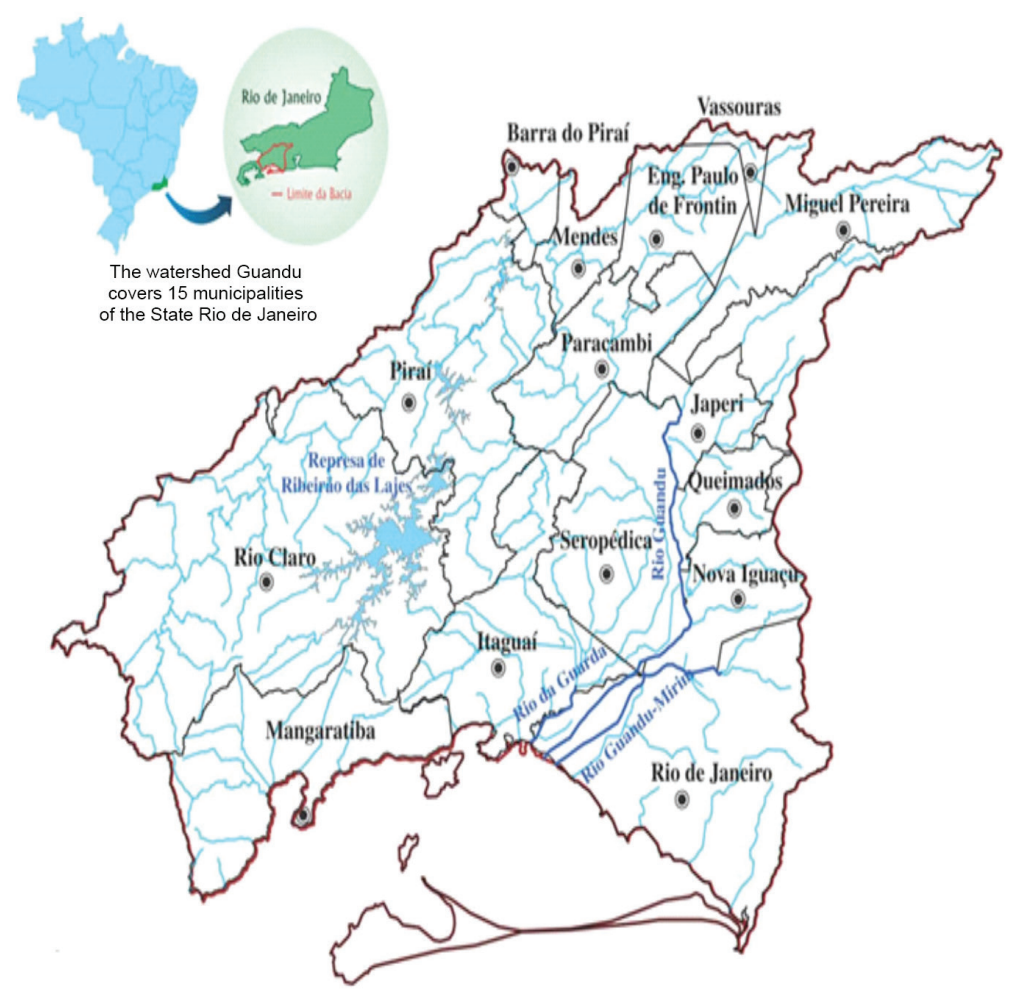

Figure 1. Map of the state of Rio de Janeiro with the sampling locations. 


\section{Experimental}

\section{Chemicals and materials}

Methanol (MeOH) HPLC grade was purchased from J.T. Baker (Phillipsburg, NJ, USA). Acetonitrile (ACN) HPLC grade, hydrochloric acid $(\mathrm{HCl})$ and formic acid (FOA) analytical grade were purchased from Merck (Darmstadt, Germany). Ascorbic acid (ASA), sodium hydroxide $(\mathrm{NaOH})$ and acetone (ACE) were purchased from Merck (Darmstadt, Germany). Ethylenediaminetetracetic acid disodium dihydrate (EDTA) was acquired from Calbiochem (Gibbstown, NJ, USA). Ultrapure water was obtained from a Milli-Q purification system (Millipore, Bedford, MA, USA). Certified reference standards of oxytetracycline (OTC), doxycycline hyclate (DC), hydrochloride salts of chlortetracycline (CTC), demeclocycline (DMC), dapsone (DAP), sulfacetamide (SCT), sulfadimethoxin (SDM), sulfamerazine (SFM), sulfamethazine (SMT), sulphaquinoxaline (SQN), sulfathiazole (STZ), tylosin tartarate (TYL), troleandomycin (TRO), erythromycin (ERY), cephapirin sodium salt (CPPN), ceftiofur (CFTF), cefoperazone (CFPZ), benzylpenicillin sodium salt (PENG), oxacillin sodium salt hydrate (OXA), moxifloxacin (MXF) and ofloxacin (OFX) were supplied from US Pharmacopeial Convention (Rockville, MD, USA). Amoxicillin tryhidrate (AMOX), ampicillin (AMPI), cefaclor (CFCL), cefadroxila (CFDX), cefalexin hydrate (CFLX), cefazolin (CFZL), clarithromycin (CLA), ciprofloxacin hydrochloride (CPF), norfloxacin (NOR), tetracycline hydrochloride (TC), sulfamethoxazole (SMZ) were chemical reference substances from the Brazilian Pharmacopeial Convention (Santa Maria, RS, Brazil). Methacycline (MTC), 4-epioxytetracycline (4-EOTC), 4-epitetracycline (4-ETC), 4-epichlortetracycline hydrochloride (4-ECTC), were acquired from Acros (Pittsburgh, PA, USA). Azithromycin dehydrate (AZI), roxithromycin (ROX), spiramycin (SPI), oleandomycin (OLE), tilmicosin (TILM), and cefquinome sulphate salt (CFQN) were obtained from Dr. Ehrenstorfer (Augsburg, Germany). Phenoxymethylpenicillin potassium salt (PENV), cloxacillin sodium salt hydrate (CLOX), dicloxacillin sodium salt hydrate (DCLOX) and nafcillin sodium salt (NAFC) were supplied from WHO Collaborating
Centre for Chemical Reference Substances (Stockholm, Sweden). Desacetylcephapirin (DESAC) was supplied from Bristol-Myers Squibb (New York, USA). Ampicillin- $d_{5}$ (AMPID5) was purchased from Purity Grade Standards (San Francisco, CA, USA). Solid-phase extraction (SPE) was performed with $60 \mathrm{mg}$ Oasis ${ }^{\circledR}$ HLB cartridges from Waters Corp. (Milford, MA, USA). Membrane filters of polyvinylidene fluoride (PVDF) with pore size $0.22 \mu \mathrm{m}$ were purchased from Millipore (Billerica, MA, USA).

\section{Standard solutions}

Stock solutions of $1 \mathrm{mg} \mathrm{L}^{-1}$ were prepared in $\mathrm{MeOH}$ for $\mathrm{MC}, \mathrm{SF}$ and $\mathrm{TC}$, in ultrapure water for $\mathrm{BL}$ and in $0.03 \mathrm{~mol} \mathrm{~L}^{-1} \mathrm{NaOH}$ for FQ. Stock solutions of DMC (1 $\mathrm{mg} \mathrm{L}^{-1}$ ) and AMPID5 (1 $\mathrm{mg} \mathrm{L}^{-1}$ ) were prepared using $\mathrm{MeOH}$ and ultrapure water, respectively. All stock solutions were stored at $\leq-70{ }^{\circ} \mathrm{C}$.

DMC was used as internal standard/surrogate for SF and TC quantification. AMPID5 was used as internal standard for BL, MC and FQ.

\section{Sampling and sample preparation}

Water samples used for the development and validation

An aliquot of $250 \mathrm{~mL}$ of each water sample was collected in polypropylene bottles, identified and transported under refrigeration to the laboratory for analysis. DW samples were taken from the tap at the National Institute for Quality Control in Health/Oswaldo Cruz Foundation (Rio de Janeiro, RJ), from the residences in the city of Barra Mansa and from the city of São Gonçalo (Rio de Janeiro). SW samples were collected from some rivers that make up the Guandu system (Guandu and Queimados rivers), which is the main source of the DW supply for the greater metropolitan area of Rio de Janeiro and Parado River in the Lidice District of Rio Claro, in the state of Rio de Janeiro, Brazil. A total of six samples were collected for validation, according to Table 1. Water samples were first filtered using $8 \mu \mathrm{m}$ paper filters from Whatman (England), followed by $0.22 \mu \mathrm{m}$ PVDF membrane filters (Millipore, Billerica, MA, USA). Water samples were used for method development experiments. They proved to be blank samples in previous

Table 1. Sample collection for validation

\begin{tabular}{|c|c|c|c|c|}
\hline \multirow{2}{*}{ Type } & \multicolumn{2}{|c|}{ Surface water (SW) } & \multicolumn{2}{|l|}{ Drinking water (DW) } \\
\hline & Location & Sample & Location & Sample \\
\hline 1 & Guandu River & SW1 & National Institute for Quality Control in Health/Oswaldo Cruz Foundation & DW1 \\
\hline 2 & Queimados River & SW2 & Barra Mansa & DW2 \\
\hline 3 & Parado River & SW3 & São Gonçalo & DW3 \\
\hline
\end{tabular}


analysis, for this reason they were used for all validation experiments.

\section{Water samples collected for method application}

The method was applied to analyze nine SW samples collected in June 2016 from Guandu River (Paraíba do Sul, Piraí, Macacos, Queimados, Guandu and Santana rivers, Guandu lagoon mouth, Guandu main dam and adductor to Ribeirão das Lajes River). Figure 1 shows sampling sites position. In addition, ten DW samples were collected in July 2016, from residences in Rio de Janeiro State (Barra Mansa, Belford Roxo, Resende, Rio de Janeiro and Volta Redonda cities).

The sample codes and GPS coordinates are listed in Table 2 referring to the SW samples. The objective of this investigation was to determine the selected antimicrobials residues in surface and drinking water in the state of Rio de Janeiro, Brazil.

\section{SPE procedure}

The following procedure was developed based on US EPA method $1694^{16}$ and on a previously published method for TC and SF analysis in river SW. ${ }^{12}$

A $50 \mathrm{~mL}$ aliquot of each sample (SW and DW) was spiked at $100 \mathrm{ng} \mathrm{L}^{-1}$ (BL, MC, FQ, SF and TC) and spiked with $100 \mathrm{ng} \mathrm{L}^{-1}$ of internal standards/surrogate (DMC and AMPID5). Then, the samples were acidified to $\mathrm{pH} 2.5$ with $\mathrm{HCl}$, and $2 \mathrm{~mL}$ of $25 \mathrm{mg} \mathrm{L}^{-1}$ EDTA stock solution was added. For the sample DW, it was added $2 \mathrm{~mL}$ of $625 \mathrm{mg} \mathrm{L}^{-1}$ ASA to reduce any residual chlorine that had been added as a disinfectant. This solution was applied to an Oasis $\mathrm{HLB}^{\circledR}$ cartridge previously conditioned with $3 \mathrm{~mL}$ of $\mathrm{MeOH}, 3 \mathrm{~mL}$ of ultrapure water and $3 \mathrm{~mL}$ of ultrapure water acidified to $\mathrm{pH} 2.5$ with $\mathrm{HCl}$. A manifold vacuum from Alltech (Deerfield, IL, USA) was used for SPE. The samples were percolated at a flow rate of approximately
$3 \mathrm{~mL} \mathrm{~min}{ }^{-1}$. Cartridges were washed twice with $2 \mathrm{~mL}$ of ultrapure water and then dried under vacuum $(-35 \mathrm{kPa})$ for $2 \mathrm{~min}$. Antimicrobials were eluted with three portions of $2 \mathrm{~mL}$ methanol and one portion of $2 \mathrm{~mL} \mathrm{ACE}$, using gravity flow only. $4 \mathrm{~mL}$ aliquots of the eluate were transferred to two centrifuge tubes and evaporated to dryness under $\mathrm{N}_{2}$ in a temperature up to $47{ }^{\circ} \mathrm{C}$, using an evaporator with nitrogen flow (Pierce Reacti-Therm IIITM and Pierce Reacti VapTM III, Rockford, IL, USA). The dry residues were reconstituted with $1 \mathrm{~mL}$ of $0.1 \%$ FOA:MeOH (80:20, v/v) for TC and SF analysis (diluent 1$)$ and $1 \mathrm{~mL}$ of $\mathrm{MeOH}: \mathrm{H}_{2} \mathrm{O}(65: 35$, v/v) for BL, MC and FQ analysis (diluent 2), vortexed for $30 \mathrm{~s}$ and filtered through a $0.22 \mu \mathrm{m}$ polyvinylidene fluoride (PVDF) syringe filter into amber auto-sampler vials.

\section{LC-MS/MS instrumentation}

An LC-MS/MS system consisting in a Shimadzu Prominence HPLC instrument (Shimadzu, Kyoto, Japan) equipped with a solvent delivery pump (LC-20AD), a quaternary gradient kit, a membrane degasser (DGU-20A5), an auto-sampler (SIL-20AC), a column oven (CTO-20AC), a system controller (CBM-20A) interfaced to a triple quadrupole mass spectrometer (API5000, Applied Biosystems/MDS Sciex, Foster City, CA, USA) with a TurboIonSpray ${ }^{\circledR}$ ESI source was used. Analyst ${ }^{\circledR}$ V1.4.2 LC/MS software was used for data acquisition. Positive electrospray ionization technique (ESI+) in multiple reaction monitoring (MRM) acquisition mode was used to monitor two ions for each substance. Nitrogen was employed as nebulizer gas (Gas 1, 40 psi), dryer gas (Gas 2, $40 \mathrm{psi}$ ), collision-activated dissociation (CAD) gas (6 a.u.) and Curtain $^{\mathrm{TM}}$ gas (10 psi). Other parameters selected during automatic tuning were: ion spray potential $=5000 \mathrm{~V}$; source temperature $=500{ }^{\circ} \mathrm{C}(\mathrm{SF}$ and TC $), 550{ }^{\circ} \mathrm{C}(\mathrm{BL}, \mathrm{MC}$ and FQ); entrance potential $=10 \mathrm{~V}$. The column temperature

Table 2. Sampling site details and GPS coordinates (surface sample (SW) samples)

\begin{tabular}{|c|c|c|c|}
\hline Sample & Location & Source & GPS coordinates \\
\hline RPS-01 & Barra do Piraí & Paraíba do Sul River & $22^{\circ} 28^{\prime} 56.81^{\prime \prime} \mathrm{S} / 43^{\circ} 50^{\prime} 20.45^{\prime \prime} \mathrm{W}$ \\
\hline RPI-02 & Piraí & Piraí River & $22^{\circ} 37^{\prime} 41.90^{\prime \prime} \mathrm{S} / 43^{\circ} 53^{\prime} 49.22^{\prime \prime W}$ \\
\hline RLL-03 & Piraí & adductor to the Ribeirão das Lajes River & $22^{\circ} 41^{\prime} 31.43^{\prime \prime} \mathrm{S} / 43^{\circ} 51^{\prime} 44.38^{\prime \prime} \mathrm{W}$ \\
\hline RMC-05 & Paracambi & Macacos River & $22^{\circ} 38^{\prime} 5.999^{\prime \prime} / 43^{\circ} 42^{\prime} 17.79 ’ \mathrm{~W}$ \\
\hline RSA-06 & Japeri & Santana River & $22^{\circ} 38^{\prime} 13.87^{\prime \prime} \mathrm{S} / 43^{\circ} 40^{\prime} 5.58^{\prime \prime} \mathrm{W}$ \\
\hline RGN-08 & Queimados & Guandu River & $22^{\circ} 43^{\prime} 40.35^{\prime \prime} \mathrm{S} / 43^{\circ} 38^{\prime} 26.18^{\prime \prime} \mathrm{W}$ \\
\hline RQM-10 & Queimados & Queimados River & $22^{\circ} 44^{\prime} 45.90^{\prime \prime} \mathrm{S} / 43^{\circ} 36^{\prime} 42.37^{\prime \prime} \mathrm{W}$ \\
\hline LGA-15 & Nova Iguaçu & Guandu lagoon mouth & $22^{\circ} 48^{\prime} 21.37^{\prime \prime} \mathrm{S} / 43^{\circ} 37^{\prime} 38.48^{\prime \prime} \mathrm{W}$ \\
\hline RGN-17 & Nova Iguaçu & Guandu main dam & $22^{\circ} 48^{\prime} 31.69^{\prime \prime} \mathrm{S} / 43^{\circ} 37^{\prime} 39.44^{\prime \prime} \mathrm{W}$ \\
\hline
\end{tabular}


was set at $25^{\circ} \mathrm{C}$ for $\mathrm{TC}$ and SF method and $35^{\circ} \mathrm{C}$ for $\mathrm{BL}$, $\mathrm{MC}$ and FQ method. The injection volume was $25 \mu \mathrm{L}$ for both methods. The autosampler was set at $4{ }^{\circ} \mathrm{C}$. An analytical column Pursuit ${ }^{\mathrm{TM}} \mathrm{RS}$ C18 $(100 \times 2 \mathrm{~mm}$ id, $3 \mu \mathrm{m}$ particle size, $200 \AA$ ) with a respective guard column (Agilent, Santa Clara, CA, USA) was used. Mobile phases $\mathrm{A}, \mathrm{B}$ and $\mathrm{C}$ were prepared using $\mathrm{H}_{2} \mathrm{O}, \mathrm{ACN}$ and $\mathrm{MeOH}$, respectively, all of them with $0.1 \%$ FOA. Injection volumes and the gradient elution programs were described in Table 3. ${ }^{12,17}$

Fragmentation studies with beta-lactams and fluoroquinolones for tuning the mass spectrometer were performed with mixed standard solutions at concentrations between 50 and $100 \mathrm{ng} \mathrm{mL}^{-1}$ in MeOH:1\% FOA (50:50, v/v). ESI+ in multiple reaction monitoring (MRM) acquisition mode was used to monitor two ions for each substance. MRM experiments for TC analysis in electrospray positiveion mode (ESI+) were described by Spisso et al. ${ }^{17}$ for SF by Monteiro et al. $;{ }^{12}$ for MC by Spisso et al. ${ }^{18}$ and Costa et al. ${ }^{19}$ and the analytical conditions used were listed in Table 3.

Validation

The validation of optimized method was performed according to protocol for $\mathrm{EPA}^{20}$ approval of new methods for organic and inorganic analytes in wastewater and DW. Validation method was further evaluated in terms of sensitivity, initial precision and recovery (IPR), intermediate precision and linearity.

Sensitivity (method limits of detection (LOD) and method limits of quantification (LOQ))

The method limits of detection (LOD) is calculated using seven replicates of river (SW) and drinking water (DW) samples spiked in concentration of $20 \mathrm{ng} \mathrm{L}^{-1}$. The LODs were calculated by multiplying the standard deviation from the seven measurements by the Student's $t$-test value for six degree of freedom at $99 \%$ confidence level (3.143). The LOQ were calculated by multiplying 3.18 times the LOD.

Initial precision and recovery (IPR)

The IPR for each compound was determined spiking four replicates at $100 \mathrm{ng} \mathrm{L}^{-1}$ in three samples of water from different origins (DW1, DW2, DW3, SW1, SW2 and SW3). A total of twelve samples of each type (DW and SW) were analyzed. The spiked samples were proceeded by SPE and then analyzed by LC-MS/MS.

The overall recovery was obtained comparing the analyte response in the extract of water samples (SW and DW) post-extraction reconstituted with $1 \mathrm{~mL}$ of $100 \mathrm{ng} \mathrm{L}^{-1}$ solutions (BL, MC, FQ, SF, TC, DMC and AMPID5) prepared with respective dilution solvents, $1 \mathrm{~mL}$ of diluent 1 and $1 \mathrm{~mL}$ of diluent 2 , and the theoretical concentration in the final extract assuming $100 \%$ SPE recovery. Precision was assessed with respect to repeatability (intraday precision) and intermediate precision.

\section{Linearity}

A six-point calibration set was freshly prepared by spiking varying levels of working standard solutions in ultrapure water. The analytical curves for all analytes in the concentration range from 25 to $1000 \mathrm{ng} \mathrm{L}^{-1}$ were constructed in order to quantify the analytes in the SW and DW samples.

\section{Results and Discussion}

\section{Development of the LC-MS/MS method}

MRM acquisition mode is the most suitable for quantification due to its sensitivity and specificity. Declustering potential (DP), collision energy (CE) and

Table 3. Gradient elution programs for sulfonamides (SF), tetracyclines (TC), beta-lactams (BL), macrolides (MC), fluoroquinolones (FQ)

\begin{tabular}{|c|c|c|c|c|c|c|c|c|c|}
\hline \multicolumn{5}{|c|}{ TC and SF method } & \multicolumn{5}{|c|}{ BL, MC and FQ method } \\
\hline time / min & $\mathrm{A}^{\mathrm{a} / \%}$ & $\mathrm{~B}^{\mathrm{a}} / \%$ & $\mathrm{Ca} / \%$ & $\begin{array}{l}\text { Flow rate / } \\
\left(\mathrm{mL} \min ^{-1}\right)\end{array}$ & time / min & $\mathrm{A}^{\mathrm{a}} / \%$ & $\mathrm{~B}^{\mathrm{a}} / \%$ & $\mathrm{Ca} / \%$ & $\begin{array}{l}\text { Flow rate / } \\
\left(\mathrm{mL} \mathrm{min}^{-1}\right)\end{array}$ \\
\hline 1 & 80 & 5 & 15 & 0.15 & 4.00 & 41 & 0 & 59 & 0.25 \\
\hline 15 & 60 & 25 & 15 & 0.15 & 4.10 & 0 & 50 & 50 & 0.30 \\
\hline 16 & 5 & 5 & 90 & 0.15 & 10.00 & 0 & 50 & 50 & 0.30 \\
\hline 26 & 5 & 5 & 90 & 0.15 & 10.10 & 41 & 0 & 59 & 0.30 \\
\hline 27 & 80 & 5 & 15 & 0.15 & 14.00 & 41 & 0 & 59 & 0.30 \\
\hline 35 & 80 & 5 & 15 & 0.15 & 14.10 & 41 & 0 & 59 & 0.25 \\
\hline- & - & - & - & - & 16.00 & 41 & 0 & 59 & 0.25 \\
\hline
\end{tabular}

${ }^{\mathrm{a}} \mathrm{A}, \mathrm{B}, \mathrm{C}$ : mobile phases with $0.1 \%$ FOA prepared using $\mathrm{H}_{2} \mathrm{O}, \mathrm{ACN}$ and $\mathrm{MeOH}$, respectively. 
collision cell exit potential (CXP) values for MC, SF, $\mathrm{TC}, \mathrm{BL}$ and $\mathrm{FQ}$ precursor/product ion pairs obtained in MRM mode are shown in Table 4. For BL and FQ, only protonated molecules $[\mathrm{M}+\mathrm{H}]^{+}$were observed and selected as precursor ions, and no adducts were noted. The two most abundant fragment ions were monitored for each compound. For target analytes, the most abundant transition was used for quantification purposes, whereas the second was used to confirm the identity of the substances.

The transition ERY- $\mathrm{H}_{2} \mathrm{O}$ could be monitored, because at $\mathrm{pH}$ below 7, ERY is immediately converted into its main degradation product ERY- $\mathrm{H}_{2} \mathrm{O} .{ }^{21}$ All compounds showed a good chromatographic peak resolution.

Two chromatographic methods were developed to obtain an increase in substances sensitivity, because the physicochemical properties of the five antimicrobials classes analyzed were different. Both methods were used according to polarity and extraction of different pharmaceuticals.

\section{SPE procedure}

Sample preparation is a crucial step in environmental analysis. It is highly influenced by the physical and chemical properties of the studied analytes and the matrices. The main objectives are to concentrate the analytes in the sample, remove matrix interferences and prepare the analyte in the form suitable for subsequent chromatographic analysis. Usually, the sample preparation step includes adjusting the $\mathrm{pH}$ of the solution, plus the use of a chelator (EDTA) followed by an extraction procedure, extract treatment and final preparation for the following chromatographic analysis. In most of the methods presented in the literature, Oasis $\mathrm{HLB}^{\circledR}$ cartridge has been used. This cartridge usually works at a neutral $\mathrm{pH}$. Because of their chemical composition (the combination of lipophilic divinylbenzene and hydrophilic $N$-vinylpyrrolidone polymers), they are capable of extracting acidic, neutral and basic compounds at a wide range of $\mathrm{pH}$ values including neutral $\mathrm{pH}^{8,21-26}$

EDTA was used as a chelating agent, it is recommended in the analysis of antibiotic residues in environmental samples. A chelating agent was added to water samples, prior to extraction, in order to chelate metals that are found in water, making possible to achieve good extraction efficiencies. ${ }^{21}$

Ascorbic acid (ASA) was added to remove residual chlorine in DW, because it can react with some antibiotics, including CPF, CTC, DC, ERY, OTC, sulfamethoxazole and TC. ${ }^{27,28}$ It is important to do the removal of free chlorine in water samples, because this fact leads to a more precise analysis and resulting in a reliable data, without affecting the stability of the antibiotics in water.

DMC and AMPID5 were used as surrogate standards, they were added to the samples before extraction and were also used for the quantification of the samples. Internal standard/surrogate was therefore added to the sample to compensate the losses originated from both the sample preparation procedure and from matrix effects.

Table 5 presents the comparison between the developed method and the 1694 US EPA method. ${ }^{16}$ The lower amount of sample, consumables and time show that as a result, the developed method is faster and cheaper than the 1694 US EPA method. ${ }^{16}$

\section{Validation}

Drug residues are frequently detected and quantified in aquatic environments. Unreliable analytical data can lead to misinterpretation and wrong decision-making. Therefore, the validation of the analytical method is important to obtain a correct analysis of the possible effects of these compounds on human health, as well as on non-target organisms. Methods developed by laboratories, that is, non-standardized, should be validated. Therefore, the validation of the analytical method is an important step to assure the reliability of the results and hence to enable a correct analysis of the possible effects of these compounds on human health, as well as on non-target organisms.

\section{Sensitivity (LOD and LOQ)}

The LOD and LOQ were estimated from the injection of spiked real samples (SW and DW). Results for each matrix are presented in Table 6 (SW) and Table 7 (DW). LODs calculated for SW samples were from 1 to $12 \mathrm{ng} \mathrm{L}^{-1}$ and for DW samples were from 0.15 to $20 \mathrm{ng} \mathrm{L}^{-1}$. LOQs ranged from approximately 3 to $38 \mathrm{ng} \mathrm{L}^{-1}$ for SW samples and from 0.5 to $64 \mathrm{ng} \mathrm{L}^{-1}$ for DW samples. It is worth mentioning that in the validated method, low LODs and LOQs were achieved for all antibiotics, even though low sample volumes were used for sample preconcentration. By reducing sample volume of complex samples such as river water samples, a decrease in matrix effects may be achieved.

IPR

The achieved recoveries for all target compounds ranged from 49 to $117 \%$ and from 50 to $110 \%$ for SW 
Table 4. $\mathrm{LC}-\mathrm{MS} / \mathrm{MS}$ conditions for beta-lactams (BL), macrolides (MC), fluoroquinolones (FQ), tetracyclines (TC) and sulfonamides (SF)

\begin{tabular}{|c|c|c|c|c|c|}
\hline Substance & $\begin{array}{l}\text { Precursor } \\
\text { ion }(\mathrm{m} / \mathrm{z})\end{array}$ & $\begin{array}{c}\text { Product ion } \\
(\mathrm{m} / \mathrm{z})\end{array}$ & $\mathrm{DP}^{\mathrm{a}} / \mathrm{V}$ & $\mathrm{CE}^{\mathrm{b}} / \mathrm{V}$ & $\mathrm{CXP}^{\mathrm{c}} / \mathrm{V}$ \\
\hline \multirow[t]{2}{*}{$\overline{\mathrm{CTC}}$} & 479.23 & 444.00 & 121 & 29 & 16 \\
\hline & & 462.01 & & 23 & 16 \\
\hline \multirow[t]{2}{*}{ DMC } & 465.21 & 448.10 & 106 & 25 & 16 \\
\hline & & 430.10 & & 33 & 16 \\
\hline \multirow[t]{2}{*}{$\overline{\mathrm{DC}}$} & 445.31 & 428.10 & 96 & 27 & 16 \\
\hline & & 321.20 & & 43 & 12 \\
\hline \multirow[t]{2}{*}{ MTC } & 443.26 & 426.10 & 126 & 25 & 16 \\
\hline & & 201.10 & & 49 & 16 \\
\hline \multirow[t]{2}{*}{$\overline{\text { OTC }}$} & 461.20 & 426.20 & 52 & 29 & 34 \\
\hline & & 443.40 & & 19 & 32 \\
\hline \multirow[t]{2}{*}{$\mathrm{TC}$} & 445.27 & 410.10 & 126 & 27 & 16 \\
\hline & & 427.10 & & 19 & 14 \\
\hline \multirow[t]{2}{*}{ 4-ECTC } & 479.22 & 462.00 & 91 & 25 & 16 \\
\hline & & 444.10 & & 31 & 14 \\
\hline \multirow[t]{2}{*}{ 4-EOTC } & 461.19 & 426.20 & 77 & 29 & 16 \\
\hline & & 444.00 & & 23 & 16 \\
\hline \multirow[t]{2}{*}{ 4-ETC } & 445.27 & 410.10 & 96 & 29 & 14 \\
\hline & & 427.10 & & 19 & 16 \\
\hline \multirow[t]{2}{*}{$\overline{\mathrm{DAP}}$} & 249.30 & 156.00 & 156 & 21 & 20 \\
\hline & & 108.10 & & 31 & 12 \\
\hline \multirow[t]{2}{*}{$\overline{\mathrm{SCT}}$} & 215.14 & 156.10 & 71 & 15 & 16 \\
\hline & & 108.00 & & 29 & 14 \\
\hline \multirow[t]{2}{*}{ SDM } & 311.16 & 156.30 & 141 & 29 & 10 \\
\hline & & 108.10 & & 41 & 14 \\
\hline \multirow[t]{2}{*}{$\overline{\text { SFM }}$} & 265.25 & 108.20 & 96 & 37 & 10 \\
\hline & & 156.20 & & 25 & 10 \\
\hline \multirow[t]{2}{*}{$\overline{\text { SMT }}$} & 279.21 & 124.10 & 111 & 37 & 16 \\
\hline & & 204.10 & & 25 & 16 \\
\hline \multirow[t]{2}{*}{$\overline{S M Z}$} & 254.18 & 156.10 & 116 & 23 & 16 \\
\hline & & 108.20 & & 33 & 14 \\
\hline \multirow[t]{2}{*}{$\overline{\mathrm{SQN}}$} & 301.34 & 156.10 & 141 & 25 & 22 \\
\hline & & 108.10 & & 39 & 12 \\
\hline \multirow[t]{2}{*}{$\overline{\text { STZ }}$} & 256.30 & 156.10 & 91 & 21 & 16 \\
\hline & & 108.10 & & 33 & 16 \\
\hline \multirow[t]{2}{*}{$\overline{\mathrm{CFQN}}$} & 529.09 & 134.10 & 101 & 21 & 14 \\
\hline & & 125.00 & & 77 & 16 \\
\hline \multirow[t]{2}{*}{$\overline{\text { CFZL }}$} & 455.09 & 323.10 & 71 & 15 & 24 \\
\hline & & 155.90 & & 23 & 20 \\
\hline \multirow[t]{2}{*}{$\overline{\mathrm{CFCL}}$} & 368.06 & 106.10 & 86 & 33 & 14 \\
\hline & & 174.00 & & 19 & 24 \\
\hline \multirow[t]{2}{*}{$\overline{\mathrm{PENV}}$} & 351.09 & 159.90 & 56 & 15 & 20 \\
\hline & & 113.90 & & 45 & 20 \\
\hline \multirow[t]{2}{*}{$\overline{\text { AMPID5 }}$} & 355.11 & 111.00 & 111 & 27 & 18 \\
\hline & & 197.20 & & 23 & 28 \\
\hline$\overline{\mathrm{CPPN}}$ & 424.06 & 152.00 & 106 & 33 & 24 \\
\hline & & 124.00 & & 59 & 18 \\
\hline NAFC & 415.16 & 199.10 & 96 & 21 & 16 \\
\hline & & 171.00 & & 47 & 18 \\
\hline
\end{tabular}

\begin{tabular}{|c|c|c|c|c|c|}
\hline Substance & $\begin{array}{l}\text { Precursor } \\
\text { ion }(\mathrm{m} / \mathrm{z})\end{array}$ & $\begin{array}{c}\text { Product ion } \\
(\mathrm{m} / \mathrm{z})\end{array}$ & $\mathrm{DP}^{\mathrm{a}} / \mathrm{V}$ & $\mathrm{CE}^{\mathrm{b}} / \mathrm{V}$ & $\mathrm{CXP}^{\mathrm{c}} / \mathrm{V}$ \\
\hline \multirow[t]{2}{*}{ PENG } & 335.17 & 160.10 & 81 & 25 & 8 \\
\hline & & 176.00 & & 29 & 22 \\
\hline \multirow{2}{*}{ CLOX } & 436.02 & 277.20 & 86 & 19 & 20 \\
\hline & & 160.20 & & 21 & 10 \\
\hline \multirow[t]{2}{*}{ CFLX } & 348.19 & 158.00 & 71 & 13 & 16 \\
\hline & & 106.20 & & 41 & 14 \\
\hline \multirow[t]{2}{*}{ OXA } & 402.09 & 159.90 & 101 & 19 & 16 \\
\hline & & 243.00 & & 17 & 16 \\
\hline \multirow[t]{2}{*}{$\overline{\mathrm{CFTF}}$} & 524.00 & 241.00 & 121 & 23 & 16 \\
\hline & & 124.90 & & 77 & 18 \\
\hline \multirow[t]{2}{*}{ CFDX } & 364.09 & 114.10 & 71 & 27 & 14 \\
\hline & & 208.00 & & 13 & 12 \\
\hline \multirow[t]{2}{*}{ DCLOX } & 470.03 & 160.10 & 101 & 19 & 16 \\
\hline & & 311.10 & & 21 & 22 \\
\hline \multirow{2}{*}{ AMPI } & 350.16 & 106.10 & 81 & 29 & 14 \\
\hline & & 114.00 & & 41 & 16 \\
\hline \multirow{2}{*}{ CFPZ } & 646.09 & 143.00 & 111 & 45 & 20 \\
\hline & & 530.00 & & 17 & 18 \\
\hline \multirow[t]{2}{*}{ DESAC } & 382.096 & 111.10 & 106 & 63 & 14 \\
\hline & & 112.10 & & 35 & 14 \\
\hline \multirow[t]{2}{*}{ AMOX } & 366.10 & 114.00 & 91 & 31 & 14 \\
\hline & & 208.10 & & 17 & 16 \\
\hline \multirow[t]{2}{*}{ TYL } & 916.62 & 174.10 & 226 & 49 & 18 \\
\hline & & 772.40 & & 39 & 24 \\
\hline \multirow[t]{2}{*}{ SPI } & 422.37 & 174.00 & 126 & 29 & 30 \\
\hline & & 144.90 & & 19 & 22 \\
\hline \multirow[t]{2}{*}{ TRO } & 772.48 & 158.10 & 146 & 37 & 16 \\
\hline & & 586.20 & & 25 & 20 \\
\hline \multirow[t]{2}{*}{ OLE } & 688.39 & 158.20 & 136 & 35 & 20 \\
\hline & & 544.40 & & 21 & 18 \\
\hline \multirow[t]{2}{*}{ ROX } & 837.46 & 158.20 & 171 & 47 & 16 \\
\hline & & 679.50 & & 29 & 22 \\
\hline \multirow[t]{2}{*}{ TILM } & 435.34 & 174.00 & 106 & 33 & 22 \\
\hline & & 695.60 & & 19 & 22 \\
\hline \multirow[t]{2}{*}{$\overline{\text { CLA }}$} & 748.52 & 158.20 & 146 & 35 & 16 \\
\hline & & 590.20 & & 25 & 20 \\
\hline \multirow[t]{2}{*}{ ERY- $\mathrm{H}_{2} \mathrm{O}$} & 716.41 & 558.30 & 146 & 23 & 18 \\
\hline & & 158.10 & & 41 & 14 \\
\hline \multirow[t]{2}{*}{ AZI } & 749.56 & 158.10 & 80 & 35 & 12 \\
\hline & & 591.40 & & 35 & 12 \\
\hline \multirow[t]{2}{*}{ NOR } & 320.21 & 302.20 & 111 & 31 & 22 \\
\hline & & 231.10 & & 53 & 14 \\
\hline \multirow[t]{2}{*}{ CPF } & 332.21 & 231.10 & 106 & 49 & 18 \\
\hline & & 314.10 & & 31 & 24 \\
\hline OFX & 362.24 & 318.20 & 136 & 27 & 24 \\
\hline & & 261.20 & & 39 & 20 \\
\hline MXF & 402.21 & 384.10 & 126 & 31 & 28 \\
\hline & & 364.20 & & 39 & 28 \\
\hline
\end{tabular}

a Declustering potential; ${ }^{\mathrm{b}}$ collision energy; ${ }^{\mathrm{c}}$ collision cell exit potential. CTC: chlortetracycline; DMC: demeclocycline; DC: doxycycline hyclate; MTC: methacycline; OTC: oxytetracycline; TC: tetracycline hydrochloride; 4-ECTC: 4-epichlortetracycline hydrochloride; 4-EOTC: 4-epioxytetracycline; 4-ETC: 4-epitetracycline; DAP: dapsone; SCT: sulfacetamide; SDM: sulfadimethoxin; SFM: sulfamerazine; SMT: sulfamethazine; SMZ: sulfamethoxazole; SQN: sulfaquinoxaline; STZ: sulfathiazole; CFQN: cefquinome sulfate salt; CFZL: cefazolin; CFCL: cefaclor; PENV: phenoxymethylpenicillin potassium salt; AMPID5: ampicillin- $d_{5}$; CPPN: cephapirin sodium salt; NAFC: nafcillin sodium salt; PENG: benzylpenicillin sodium salt; CLOX: cloxacillin sodium salt hydrate; CFLX: cefalexin hydrate; OXA: oxacillin sodium salt hydrate; CFTF: ceftiofur; CFDX: cefadroxila; DCLOX: dicloxacillin sodium salt hydrate; AMPI: ampicillin; CFPZ: cefoperazone; DESAC: desacetylcephapirin; AMOX: amoxicillin tryhidrate; TYL: tylosin tartarate; SPI: spiramycin; TRO: troleandomycin; OLE: oleandomycin; ROX: roxithromycin; TILM: tilmicosin; CLA: clarithromycin; ERY: erythromycin; AZI: azithromycin dehydrate; NOR: norfloxacin; CPF: ciprofloxacin hydrochloride; OFX: ofloxacin; MXF: moxifloxacin. 
Table 5. Comparisons between the developed method and the 1694 US EPA ${ }^{16}$

\begin{tabular}{lcc}
\hline & Method developed & 1694 US EPA method \\
\hline Sample / mL & 50 & 1000 \\
EDTA & $2 \mathrm{~mL}$ of $25 \mathrm{mg} \mathrm{L}^{-1}$ & $500 \mathrm{mg}$ \\
Cartridge & HLB $60 \mathrm{mg}$ & HLB $1000 \mathrm{mg}$ \\
Washing water / mL & 4 & 10 \\
Drying / min & 2 & 5 \\
Solvent MeOH / mL & 6 & 18 \\
Solvent ACE / mL & 2 & 3 \\
Chromatographic & 2 & 3 \\
method & & \\
\hline
\end{tabular}

EDTA: ethylenediaminetetracetic acid. and DW samples, respectively (Tables 6 and 7). Good performance with recoveries above $75 \%$ among $80 \%$ of the 46 analytes for the surface and drinking water sample was achieved. Only PENG samples showed recovery rates below of $40 \%$. This fact can be explained by their instability in water, related to their chemical structure. ${ }^{21}$ High recoveries obtained for fluoroquinolones can be explained by the retention of these antibiotics in acidic conditions. ${ }^{21,24}$ Such recoveries are similar to those achieved by other studies depending on the analyte. . $^{8,18-23}$

In both matrices, the relative standard deviation (RSD) obtained are less than $58 \%$ for all analytes for repetitivity and repeatability, which is lower than values reported by

Table 6. Performance data for pharmaceuticals in surface water (SW)

\begin{tabular}{|c|c|c|c|c|c|c|}
\hline Class & Compound & Recovery / \% & $\begin{array}{c}\text { Repetitivity } \\
(\mathrm{RSD} / \% ; \mathrm{n}=6)\end{array}$ & $\begin{array}{c}\text { Repeatability } \\
(\mathrm{RSD} / \% ; \mathrm{n}=12)\end{array}$ & $\mathrm{LOD} /\left(\mathrm{ng} \mathrm{L}^{-1}\right)$ & $\mathrm{LOQ} /\left(\mathrm{ng} \mathrm{L}^{-1}\right)$ \\
\hline \multirow[t]{9}{*}{ Tetracycline (TC) } & CTC & 85 & 9 & 9 & 9 & 29 \\
\hline & DMC & 88 & 12 & 12 & 7 & 23 \\
\hline & $\mathrm{DC}$ & 82 & 9 & 7 & 10 & 32 \\
\hline & MTC & 91 & 16 & 11 & 6 & 19 \\
\hline & OTC & 92 & 12 & 12 & 5 & 16 \\
\hline & $\mathrm{TC}$ & 91 & 10 & 17 & 10 & 32 \\
\hline & 4-ECTC & 89 & 14 & 15 & 2 & 6 \\
\hline & 4-EOTC & 78 & 8 & 13 & 9 & 27 \\
\hline & 4-ETC & 88 & 11 & 13 & 4 & 12 \\
\hline \multirow[t]{8}{*}{ Sulfonamide (SF) } & DAP & 49 & 15 & 32 & 3 & 9 \\
\hline & SCT & 89 & 17 & 47 & 3 & 9 \\
\hline & SDM & 57 & 10 & 13 & 7 & 22 \\
\hline & SFM & 80 & 10 & 31 & 5 & 16 \\
\hline & SMT & 65 & 12 & 13 & 8 & 26 \\
\hline & SMZ & 67 & 6 & 14 & 9 & 27 \\
\hline & SQN & 62 & 14 & 17 & 6 & 20 \\
\hline & STZ & 73 & 13 & 34 & 4 & 14 \\
\hline \multirow[t]{4}{*}{ Fluoroquinolone (FQ) } & $\mathrm{CPF}$ & 97 & 19 & 58 & 12 & 38 \\
\hline & NOR & 117 & 14 & 19 & 7 & 27 \\
\hline & OFX & 109 & 22 & 31 & 6 & 18 \\
\hline & MXF & 105 & 6 & 12 & 2 & 5 \\
\hline \multirow[t]{18}{*}{ Beta-lactam (BL) } & CFQN & 104 & 32 & 18 & 3 & 8 \\
\hline & CFZL & 104 & 12 & 6 & 4 & 13 \\
\hline & CFCL & 93 & 23 & 19 & 1 & 3 \\
\hline & PENV & 101 & 13 & 12 & 2 & 6 \\
\hline & CPPN & 107 & 18 & 8 & 3 & 11 \\
\hline & NAFC & 62 & 28 & 27 & 6 & 20 \\
\hline & PENG & 33 & 22 & 37 & 8 & 24 \\
\hline & CLOX & 91 & 18 & 10 & 10 & 33 \\
\hline & CFLX & 84 & 21 & 11 & 4 & 13 \\
\hline & OXA & 90 & 17 & 15 & 3 & 10 \\
\hline & CFTF & 97 & 7 & 8 & 6 & 19 \\
\hline & CFDX & 83 & 32 & 43 & 3 & 9 \\
\hline & DCLOX & 88 & 16 & 11 & 10 & 33 \\
\hline & AMPI & 100 & 26 & 19 & 10 & 33 \\
\hline & CFPZ & 107 & 22 & 10 & 2 & 7 \\
\hline & AMOX & 77 & 36 & 50 & 6 & 20 \\
\hline & DESAC & 87 & 15 & 12 & 3 & 9 \\
\hline & AMPID5 & 97 & 14 & 8 & 2 & 7 \\
\hline
\end{tabular}


Table 6. Performance data for pharmaceuticals in surface water (SW) (cont.)

\begin{tabular}{|c|c|c|c|c|c|c|}
\hline Class & Compound & Recovery / \% & $\begin{array}{c}\text { Repetitivity } \\
(\text { RSD } / \% ; \mathrm{n}=6)\end{array}$ & $\begin{array}{c}\text { Repeatability } \\
(\mathrm{RSD} / \% ; \mathrm{n}=12)\end{array}$ & $\mathrm{LOD} /\left(\mathrm{ng} \mathrm{L}^{-1}\right)$ & $\mathrm{LOQ} /\left(\mathrm{ng} \mathrm{L}^{-1}\right)$ \\
\hline \multirow[t]{9}{*}{ Macrolide (MC) } & TYL & 73 & 26 & 17 & 8 & 25 \\
\hline & SPI & 68 & 34 & 36 & 11 & 35 \\
\hline & TRO & 84 & 28 & 17 & 4 & 14 \\
\hline & OLE & 97 & 7 & 4 & 11 & 34 \\
\hline & ROX & 86 & 18 & 28 & 5 & 16 \\
\hline & ERY & 82 & 15 & 12 & 5 & 15 \\
\hline & TILM & 71 & 49 & 41 & 5 & 14 \\
\hline & CLA & 98 & 19 & 16 & 6 & 18 \\
\hline & AZI & 92 & 15 & 12 & 4 & 11 \\
\hline
\end{tabular}

LOD: limits of detection; LOQ: limits of quantification; CTC: chlortetracycline; DMC: demeclocycline; DC: doxycycline hyclate; MTC: methacycline; OTC: oxytetracycline; TC: tetracycline hydrochloride; 4-ECTC: 4-epichlortetracycline hydrochloride; 4-EOTC: 4-epioxytetracycline; 4-ETC: 4-epitetracycline; DAP: dapsone; SCT: sulfacetamide; SDM: sulfadimethoxin; SFM: sulfamerazine; SMT: sulfamethazine; SMZ: sulfamethoxazole; SQN: sulfaquinoxaline; STZ: sulfathiazole; CPF: ciprofloxacin hydrochloride; NOR: norfloxacin; OFX: ofloxacin; MXF: moxifloxacin; CFQN: cefquinome sulfate salt; CFZL: cefazolin; CFCL: cefaclor; PENV: phenoxymethylpenicillin potassium salt; CPPN: cephapirin sodium salt; NAFC: nafcillin sodium salt; PENG: benzylpenicillin sodium salt; CLOX: cloxacillin sodium salt hydrate; CFLX: cefalexin hydrate; OXA: oxacillin sodium salt hydrate; CFTF: ceftiofur; CFDX: cefadroxila; DCLOX: dicloxacillin sodium salt hydrate; AMPI: ampicillin; CFPZ: cefoperazone; AMOX: amoxicillin tryhidrate; DESAC: desacetylcephapirin; AMPID5: ampicillin- $d_{5}$; TYL: tylosin tartarate; SPI: spiramycin; TRO: troleandomycin; OLE: oleandomycin; ROX: roxithromycin; ERY: erythromycin; TILM: tilmicosin; CLA: clarithromycin; AZI: azithromycin dehydrate.

Table 7. Performance data for pharmaceuticals in drinking water (DW)

\begin{tabular}{|c|c|c|c|c|c|c|}
\hline Class & Compound & Recovery / \% & $\begin{array}{c}\text { Repetitivity } \\
(\mathrm{RSD} / \% ; \mathrm{n}=6)\end{array}$ & $\begin{array}{c}\text { Repeatability } \\
(\mathrm{RSD} / \% ; \mathrm{n}=12)\end{array}$ & $\mathrm{LOD} /\left(\mathrm{ng} \mathrm{L}^{-1}\right)$ & $\mathrm{LOQ} /\left(\mathrm{ng} \mathrm{L}^{-1}\right)$ \\
\hline \multirow[t]{9}{*}{ Tetracycline (TC) } & CTC & 85 & 18 & 23 & 11 & 34 \\
\hline & DMC & 80 & 20 & 19 & 5 & 17 \\
\hline & $\mathrm{DC}$ & 73 & 21 & 26 & 15 & 46 \\
\hline & MTC & 86 & 11 & 26 & 12 & 39 \\
\hline & OTC & 92 & 17 & 18 & 6 & 20 \\
\hline & $\mathrm{TC}$ & 86 & 10 & 12 & 6 & 18 \\
\hline & 4-ECTC & 88 & 7 & 19 & 8 & 25 \\
\hline & 4-EOTC & 77 & 13 & 9 & 6 & 20 \\
\hline & 4-ETC & 88 & 11 & 12 & 6 & 19 \\
\hline \multirow[t]{8}{*}{ Sulfonamide (SF) } & DAP & 50 & 30 & 30 & 16 & 52 \\
\hline & SCT & 90 & 10 & 37 & 9 & 27 \\
\hline & SDM & 59 & 17 & 18 & 9 & 29 \\
\hline & SFM & 77 & 19 & 19 & 9 & 28 \\
\hline & SMT & 66 & 13 & 13 & 8 & 26 \\
\hline & SMZ & 66 & 11 & 12 & 11 & 34 \\
\hline & SQN & 53 & 21 & 19 & 11 & 34 \\
\hline & STZ & 80 & 13 & 30 & 7 & 23 \\
\hline \multirow[t]{4}{*}{ Fluoroquinolone (FQ) } & $\mathrm{CPF}$ & 99 & 19 & 11 & 12 & 38 \\
\hline & NOR & 99 & 14 & 10 & 3 & 11 \\
\hline & OFX & 94 & 22 & 12 & 5 & 16 \\
\hline & MXF & 101 & 6 & 7 & 2 & 6 \\
\hline \multirow[t]{10}{*}{ Beta-lactam (BL) } & CFQN & 72 & 16 & 26 & 9 & 29 \\
\hline & CFZL & 102 & 11 & 9 & 4 & 13 \\
\hline & CFCL & 90 & 22 & 15 & 20 & 64 \\
\hline & PENV & 105 & 10 & 5 & 8 & 24 \\
\hline & CPPN & 97 & 7 & 12 & 3 & 11 \\
\hline & NAFC & 66 & 19 & 19 & 7 & 23 \\
\hline & PENG & 37 & 26 & 23 & 5 & 15 \\
\hline & CLOX & 106 & 15 & 10 & 8 & 26 \\
\hline & CFLX & 76 & 17 & 21 & 4 & 12 \\
\hline & OXA & 97 & 10 & 8 & 7 & 22 \\
\hline
\end{tabular}


Table 7. Performance data for pharmaceuticals in drinking water (DW) (cont.)

\begin{tabular}{|c|c|c|c|c|c|c|}
\hline Class & Compound & Recovery / \% & $\begin{array}{c}\text { Repetitivity } \\
(\mathrm{RSD} / \% ; \mathrm{n}=6)\end{array}$ & $\begin{array}{c}\text { Repeatability } \\
(\mathrm{RSD} / \% ; \mathrm{n}=12)\end{array}$ & $\mathrm{LOD} /\left(\mathrm{ng} \mathrm{L}^{-1}\right)$ & $\mathrm{LOQ} /\left(\mathrm{ng} \mathrm{L}^{-1}\right)$ \\
\hline \multirow[t]{8}{*}{ Beta-lactam (BL) } & CFTF & 94 & 10 & 15 & 9 & 29 \\
\hline & CFDX & 65 & 27 & 29 & 4 & 11 \\
\hline & DCLOX & 103 & 20 & 12 & 6 & 19 \\
\hline & AMPI & 82 & 16 & 14 & 14 & 44 \\
\hline & CFPZ & 102 & 8 & 9 & 6 & 20 \\
\hline & AMOX & 84 & 25 & 33 & 5 & 16 \\
\hline & DESAC & 99 & 8 & 9 & 3 & 10 \\
\hline & AMPID5 & 95 & 8 & 10 & 5 & 14 \\
\hline \multirow[t]{9}{*}{ Macrolide (MC) } & TYL & 85 & 20 & 9 & 3 & 10 \\
\hline & SPI & 62 & 35 & 30 & 4 & 12 \\
\hline & TRO & 97 & 16 & 24 & 4 & 12 \\
\hline & OLE & 110 & 12 & 4 & 5 & 17 \\
\hline & ROX & 91 & 12 & 20 & 3 & 10 \\
\hline & ERY & 85 & 23 & 21 & 0.15 & 0.5 \\
\hline & TILM & 83 & 40 & 31 & 4 & 13 \\
\hline & CLA & 101 & 9 & 10 & 4 & 11 \\
\hline & AZI & 104 & 13 & 13 & 9 & 27 \\
\hline
\end{tabular}

LOD: limits of detection; LOQ: limits of quantification; CTC: chlortetracycline; DMC: demeclocycline; DC: doxycycline hyclate; MTC: methacycline; OTC: oxytetracycline; TC: tetracycline hydrochloride; 4-ECTC: 4-epichlortetracycline hydrochloride; 4-EOTC: 4-epioxytetracycline; 4-ETC: 4-epitetracycline; DAP: dapsone; SCT: sulfacetamide; SDM: sulfadimethoxin; SFM: sulfamerazine; SMT: sulfamethazine; SMZ: sulfamethoxazole; SQN: sulfaquinoxaline; STZ: sulfathiazole; CPF: ciprofloxacin hydrochloride; NOR: norfloxacin; OFX: ofloxacin; MXF: moxifloxacin; CFQN: cefquinome sulfate salt; CFZL: cefazolin; CFCL: cefaclor; PENV: phenoxymethylpenicillin potassium salt; CPPN: cephapirin sodium salt; NAFC: nafcillin sodium salt; PENG: benzylpenicillin sodium salt; CLOX: cloxacillin sodium salt hydrate; CFLX: cefalexin hydrate; OXA: oxacillin sodium salt hydrate; CFTF: ceftiofur; CFDX: cefadroxila; DCLOX: dicloxacillin sodium salt hydrate; AMPI: ampicillin; CFPZ: cefoperazone; AMOX: amoxicillin tryhidrate; DESAC: desacetylcephapirin; AMPID5: ampicillin- $d_{5}$; TYL: tylosin tartarate; SPI: spiramycin; TRO: troleandomycin; OLE: oleandomycin; ROX: roxithromycin; ERY: erythromycin; TILM: tilmicosin; CLA: clarithromycin; AZI: azithromycin dehydrate.

1694 US EPA method ${ }^{16}$ and high deviations may have occurred due to the validation of three different water source types. RSD values were acceptable, considering the specifications laid down by European Commission ${ }^{29}$ and by Codex Alimentarius Commission. ${ }^{30}$

The internal standard/surrogate recoveries and standard deviations for antibiotics in both SW and DW water are presented in Tables 6 and 7, respectively.

\section{Linearity}

The linearity was evaluated with matrix-matched analytical curve at six concentration levels. The results showed good linearity over the range of 25 to $1000 \mathrm{ng} \mathrm{L}^{-1}$ with coefficient of determination $\left(\mathrm{R}^{2}\right)$ greater than 0.97 for SW and greater than 0.94 for DW.

\section{Method application}

The method was applied to the analysis of nine SW and ten DW samples. According to the results, showed in Table 8, compounds were found present in eight out of nine SW samples. Antibiotics were not detected only in the adductor to the Ribeirão das Lajes SW samples. The results showed levels of AMOX, CFLX and SMZ as higher as $105 \mathrm{ng} \mathrm{L}^{-1}$. Also, concentrations of ERY, AZI, CLA up to $35 \mathrm{ng} \mathrm{L}^{-1}$ could be found in the river water.

CLA, CFCL, OXA, SMZ and TRO were detected in the lower range up to $10 \mathrm{ng} \mathrm{L}^{-1}$ in DW water (Table 9).

Figure 2 shows the MRM chromatograms of a contaminated SW samples with a maximum concentration of AMOX, CFLX, SMZ, ERY, AZI and CLA. The other antibiotics analyzed were below the method limits of detection (LOD).

Many compounds have been found worldwide in several different types of water. A recent review described that among 22 pharmaceuticals detected in SW around the world, about 13 are common in Brazil and other countries, being the most commonly detected antibiotics. ${ }^{9}$ Studies conducted by Locatelli et al. ${ }^{10}$ and Monteiro et al. ${ }^{11}$ in rivers located in São Paulo, Brazil, showed that NOR, AMOX, CFLX, CPF, SMZ, TC, trimethoprim, OTC and florfenicol were determined with a concentration between 2.2 and $484 \mathrm{ng} \mathrm{L}^{-1}$ and in a river in Rio de Janeiro, Brazil, OTC and SMZ were detected in concentration between 44.1 and $467 \mathrm{ng} \mathrm{L}^{-1}$, respectively. ${ }^{12} \mathrm{In} \mathrm{SW}$ samples from Dilúvio 
Table 8. River water results for surface water (SW) samples

\begin{tabular}{lcccccccc}
\hline \multirow{2}{*}{ Analyte } & \multicolumn{1}{c}{ SW samples / (ng L $\left.{ }^{-1}\right)$} \\
\cline { 2 - 8 } & $\begin{array}{c}\text { Paraiba do Sul } \\
\text { River }\end{array}$ & $\begin{array}{c}\text { Macacos } \\
\text { River }\end{array}$ & $\begin{array}{c}\text { Queimados } \\
\text { River }\end{array}$ & $\begin{array}{c}\text { Guandu } \\
\text { main dam }\end{array}$ & $\begin{array}{c}\text { Piraí } \\
\text { River }\end{array}$ & $\begin{array}{c}\text { Guandu } \\
\text { Lagoon }\end{array}$ & $\begin{array}{c}\text { Santana } \\
\text { River }\end{array}$ & $\begin{array}{c}\text { Guandu } \\
\text { River }\end{array}$ \\
\hline AMOX & 38.0 & 287.5 & ND & ND & ND & ND & ND & ND \\
SMZ & DE & 60.3 & 105.0 & DE & DE & DE & DE & DE \\
CLA & DE & DE & 39.2 & DE & ND & ND & ND & ND \\
CFLX & ND & 575.5 & ND & ND & ND & ND & ND & ND \\
ERY-H ${ }_{2} \mathrm{O}$ & ND & ND & DE & DE & DE & DE & ND & ND \\
AZI & ND & ND & 35.9 & ND & ND & ND & ND & ND \\
\hline
\end{tabular}

DE: detected (> limit of detection (LOD); < limit of quantification (LOQ)); ND: not detected (<LOD). AMOX: amoxicillin tryhidrate; SMZ: sulfamethoxazole; CLA: clarithromycin; CFLX: cefalexin hydrate; ERY: erythromycin; AZI: azithromycin dehydrate.

Table 9. River water results for drinking water (DW) samples

\begin{tabular}{lcccccc}
\hline \multirow{2}{*}{ Analyte } & \multicolumn{3}{c}{ DW samples / (ng L $\left.{ }^{-1}\right)$} \\
\cline { 2 - 7 } & Rio de Janeiro & Belford Roxo & Barra Mansa & Volta Redonda & Resende & São Gonçalo \\
\hline CFCL & DE & ND & ND & ND & DE & ND \\
SMZ & ND & DE & ND & ND & DE & DE \\
CLA & ND & DE & DE & ND & ND & ND \\
TRO & ND & ND & DE & ND & ND & ND \\
OXA & ND & ND & ND & DE & ND & ND \\
\hline
\end{tabular}

DE: detected; ND: not detected (below limit of detection). CFCL: cefaclor; SMZ: sulfamethoxazole; CLA: clarithromycin; TRO: troleandomycin; OXA: oxacillin sodium salt hydrate.

Creek in Porto Alegre, Brazil, SMZ, CPF, NOR and AZI were detected between 15.7 and $572 \mathrm{ng} \mathrm{L}^{-1} .^{13}$

The non-detection of TCs in water samples may be due to their strong adsorption on organic matter and, although TCs are very soluble in water and are weakly adsorbed by biomass, mechanisms like metal complexation likely played a significant role in the sorption of TCs into solids. ${ }^{11,14}$ Similarly, FQs were not found in water, possibly because these molecules are strongly adsorbed by sediment, especially when the concentration of $\mathrm{Ca}^{2+}$ and $\mathrm{Mg}^{2+}$ is high. ${ }^{14}$

\section{Conclusions}

The analytical method developed and validated, based on SPE followed by LC-MS/MS analysis, for the simultaneous extraction of beta-lactams, macrolides, fluoroquinolones, sulfonamides and tetracyclines classes, showed good performance. The achieved recoveries for all target compounds ranged from 49 to $117 \%$ and from 50 to $110 \%$ for SW and DW samples, respectively. In both matrices, the obtained RSD are less than $58 \%$ for all analytes for repetitivity and repeatability, which is lower than values reported by 1694 US EPA method. As a result, a fast and cost-effective method was developed.

The developed and validated method in this study was applied to evaluate the occurrence of compounds in SW and DW from Rio de Janeiro. The results showed that several compounds are occasionally present at high levels, indicating that the evaluated rivers receive uncontrolled loads of wastewater of different sources and/or that these compounds are not efficiently removed in the wastewater treatment plant. The results highlight the worries related to the presence of these compounds in the environment, because of their possible ecotoxicological effects on non-target organisms and on human health arising from the food chain via the water cycle.

\section{Acknowledgments}

The authors thank the Brazilian National Coordination for the Improvement of Higher Education Personnel (CAPES) for financial support. We also thank Eduardo Gomes Rodrigues de Sousa and Renata Medeiros for revising the manuscript. Marcos Consoli and Cristiane Gomes from CEDAE are acknowledged for the collection of SW samples. 

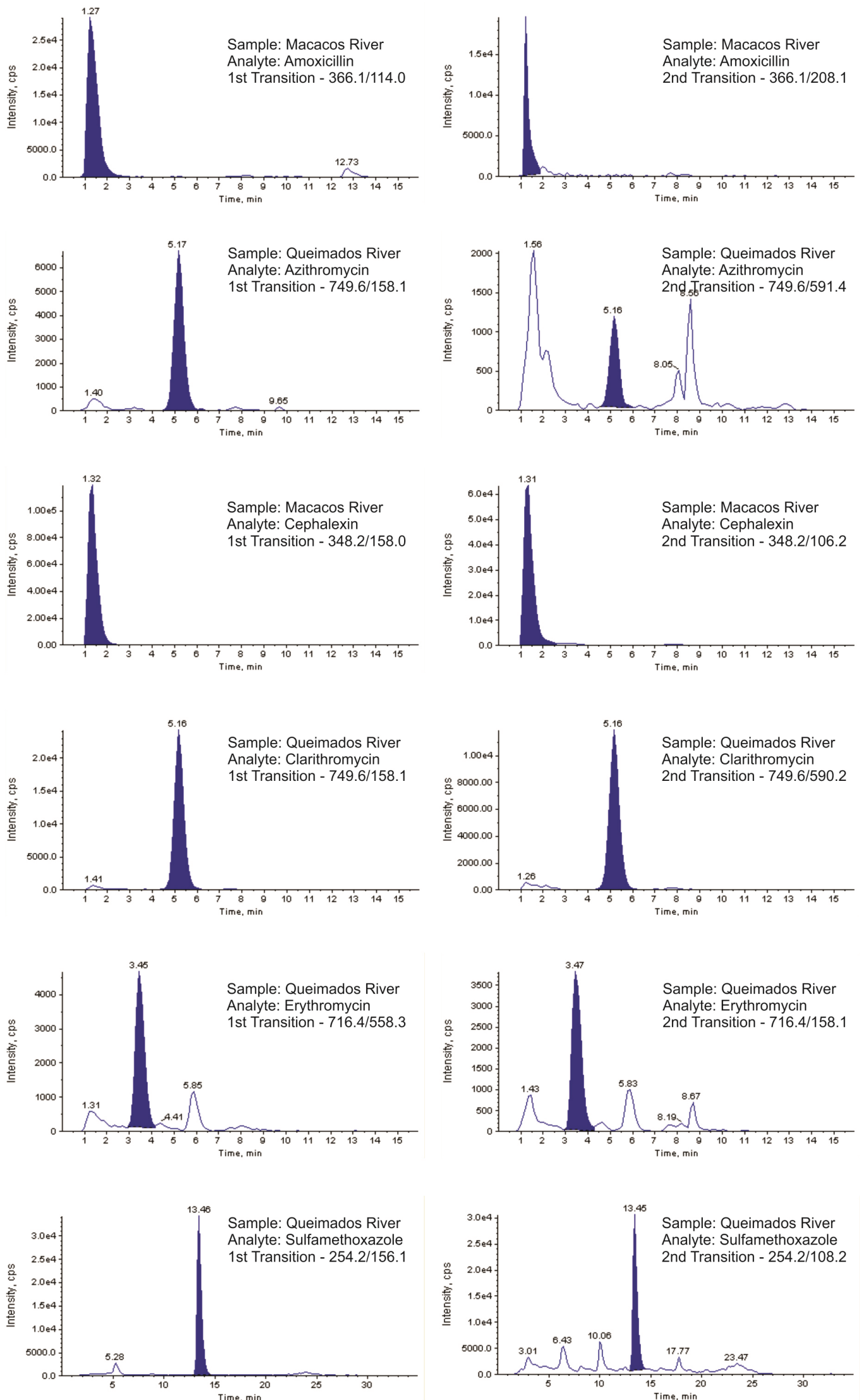

Figure 2. MRM chromatograms of the surface water samples with of amoxicillin, cefalexin, sulfamethoxazole, erythromycin, azithromycin and clarithromycin 


\section{References}

1. Walsh, C.; Antibiotics: Actions, Origins, Resistence, $1^{\text {st }}$ ed.; ASM Press: Washington, USA, 2003.

2. Lipinski, C. A.; Lombardo, F.; Dominy, B. W.; Feeney, P. J.; Adv. Drug Delivery Rev. 1997, 23, 3.

3. Heberer, T.; Toxicol. Lett. 2002, 131, 5.

4. Ikehata, K.; Naghashkar, N. J.; El-Din, M. G.; Ozone: Sci. Eng. 2006, 28, 353 .

5. Mulroy, A.; Water Environ. Technol. 2001, 13, 31.

6. Bila, D. M.; Dezotti, M.; Quim. Nova 2003, 26, 523.

7. Kümmerer, K.; J. Antimicrob. Chemother. 2004, 52, 5.

8. Gros, M.; Petrovic, M.; Barceló, D.; Anal. Bioanal. Chem. 2006, 386, 941.

9. Quadra, G. R.; Souza, H. O.; Costa, R. S.; Fernandez, M. A. S.; Environ. Sci. Pollut. Res. 2017, 24, 1200.

10. Locatelli, M. A. F.; Sodre, F. F.; Jardim, W. F.; Arch. Environ. Contam. Toxicol. 2011, 60, 385.

11. Monteiro, S. H.; Francisco, J. G.; Andrade, G. C.; Botelho, R. G.; Figueiredo, L. A.; Tornisielo, V. L.; J. Environ. Sci. Health, Part B 2016, 9, 634.

12. Monteiro, M. A.; Spisso, B. F.; Santos, J. R. M. P.; Costa, R. P.; Ferreira, R. G.; Pereira, M. U.; Miranda, T. S.; Andrade, B. R. G.; d'Avila, L. A.; J. Environ. Prot. 2016, 7, 230.

13. Jank, L.; Hoff, R. B.; Costa, F. J.; Pizzolato, T. M.; Int. J. Environ. Anal. Chem. 2014, 94, 1013.

14. Pedroso, R. C. R.; Peralba, M. C. R.; Santos, J. H. Z.; Pizzolato, T. M.; Quim. Nova 2011, 34, 206.

15. Tubbs Filho, D.; Antunes, J. C. O.; Vettorazzi, J. S.; Bacia Hidrográfica dos Rios Guandu, da Guarda e Guandu-Mirim - Experiências para a Gestão dos Recursos Hídricos, 1ª ed.; Instituto Estadual do Ambiente: Rio de Janeiro, Brasil, 2012.

16. U.S. Environmental Protection Agency (US EPA); Method 1694: Pharmaceuticals and Personal Care Products in Water, Soil, Sediment, and Biosolids by HPLC/MS/MS; U.S. Environmental Protection Agency, Office of Water: Washington, DC, USA, 2007.

17. Spisso, B. F.; Araújo Júnior, M. A. G.; Monteiro, M. A.; Lima, A. M. B.; Pereira, M. U.; Luiz, R. A.; Nóbrega, A. W. A.; Anal. Chim. Acta 2009, 656, 72.
18. Spisso, B. F.; Ferreira, R. G.; Pereira, M. U.; Monteiro, M. A.; Cruz, T. A.; Costa, R. P.; Lima, A. M. B.; Nóbrega, A. W.; Anal. Chim. Acta 2010, 682, 82.

19. Costa, R. P.; Spisso, B. F.; Pereira, M. U.; Monteiro, M. A.; Ferreira, R. G.; Nóbrega, A. W.; J. Sep. Sci. 2015, 38, 3743.

20. U.S. Environmental Protection Agency (US EPA); EPA 821B-98-003: Protocol for EPA Approval of New Methods for Organic and Inorganic Analytes in Wastewater and Drinking Water; U.S. Environmental Protection Agency, Office of Water: Washington, DC, USA, 1999.

21. Dinh, Q. T.; Alliot, F.; Moreau-Guigon, E.; Eurin, J.; Chevreuil, M.; Labadie, P.; Talanta 2011, 85, 1238.

22. Silva, C. G. A.; Collins, C. H.; Quim. Nova 2011, 34, 665.

23. Seifrtova, M.; Novakova, L.; Lino, C.; Pena, A.; Solich, P.; Anal. Chim. Acta 2009, 649, 158.

24. Gros, M.; Rodríguez-Mozaz, S.; Barceló, D.; J. Chromatogr. A 2013, 1292, 173.

25. Koreje, K. O.; Demeestere, K.; Wispelaere, P.; Vergeynst, L.; Dewulf, J.; Langenhove, H. V.; Sci. Total Environ. 2012, 437, 153.

26. Rodriguez-Navas, C.; Bjorklund, E.; Bak, S. A.; Hansen, M.; Krogh, K. A.; Maya, F.; Forteza, R.; Cerda, V.; Arch. Environ. Contam. Toxicol. 2013, 65, 56.

27. Ye, Z.; Weinberg, H. S.; Meyer, M.; Anal. Chem. 2007, 79, 1135.

28. Wang, P.; He, Y.; Huang, C.; Water Res. 2011, 45, 1838.

29. European Commission; Commission Decision 2002/657/EC (Commission Decision 2002/657). Commission Decision of 12 August 2002 Implementing Council Directive 96/23/EC Concerning the Performance of Analytical Methods and the Interpretation of Results; Official Journal of the European Communities, 2002, L221/8.

30. Codex Alimentarius Commission; CAC/GL 71-2009: Guidelines for the Design and Implementation of National Regulatory Food Safety Assurance Programme Associated with the Use of Veterinary Drugs in Food Producing Animals; Food and Agriculture Organization of the United States (FAO), World Health Organization (WHO): Geneva, 2014.

Submitted: April 25, 2017

Published online: November 17, 2017 